\title{
SURFACE SIGNS OF THE BIENNIAL ATMOSPHERIC PULSE
}

\author{
H. E. LANDSBERG, J. M. MITCHELL, JR. \\ U.S. Weather Bureau, Washington, D.C. \\ and \\ H. L. CRUTCHER, F. T. QUINLAN \\ National Weather Records Center, U.S. Weather Bureau, Asheville, N.C. \\ [Manusoript received July 1,1963 ] \\ ABSTRACT
}

\begin{abstract}
Further evidence is presented for the presence of a persistent periodicity somewhat in excess of 2 years duration. Its existence can be shown in the surface temperature at widely separated stations along two meridians from Norway to South Africa and from Canada to Cape Horn. Time series analysis by means of a narrow band-pass filter indicates phase relations among the stations, the most important of these being that the intertropical regions appear to be mutually in phase and that the higher-latitude stations are out of phase with the tropical stations. In the Northern Hemisphere, at extratropical stations, the amplitudes of the pulse are largest when the pulse extremes coincide with the winter months.
\end{abstract}

\section{INTRODUCTION}

Search for rhythmical phenomena in the atmosphere has fallen into some state of disrepute among meteorologists during the past two decades. This has been a natural reaction to the many spurious cycles which were claimed to exist in atmospheric phenomena. Some of these rhythms appeared and then vanished again and without. reasonable physical explanations they were rarely more than some statistical will-o'-the-wisp. Especially, the search for solar cycles was disappointing in observations from the lower atmosphere although their existence in ionospheric data could hardly be disputed.

It was, therefore, quite intriguing when a remarkable cyclical phenomenon was discovered in 1961 in the wind and temperature field of the equatorial stratosphere $[13,14,17,18]$. The period of these phenomena was in the range from 23 to 29 months. The observations sufficed only to trace this back for about three full oscillations but evidence for a similar fluctuation reaching in to the moderate and higher latitudes made it appear that this seemed indeed to be a widespread feature of the high-level circulation $[1,2]$.

Quite independently a similar periodicity was discovered in the concentration of atmospheric ozone in the Southern Hemisphere. This not only widens the geographical horizon but may also extend the influence of this oscillation to very high levels [7].

\section{DISCOVERY OF THE PULSE}

By the same token it had long been known that pulses of the length around or slightly above 2 years could be found in surface data. This was first discovered by Clayton. [6] in the 1880s. We noted it again in our detailed analysis of the carefully scrutinized Woodstock, Md., data [11]. In the temperature series, covering the interval from 1870 to 1956 , the 2.1 year pulse stood out among all others in the power spectrum. As a matter of continuity part of this spectrum is shown again in figure 1.

A fairly exhaustive survey of the literature [10] revealed that periods from 2 to $2.5 \mathrm{yr}$. have been found by a score of investigators in a variety of series of surface observations. including temperature, precipitation, and pressure data. In most cases this was only one cycle among others. Although its statistical significance appeared well secured. none of the earlier investigators attempted to attribute causes to it. A connection to the Southern Oscillation already suggested the worldwide aspect of the phenomenon [4]. But it is evidently also present in polar regions [9].

In spite of the fact that this pulse is deeply embedded in general atmospheric "noise" in the surface data it seemed worthwhile to pursue it further in such material. One could not expect to get such well-developed and isolated cycles as were found in the tropical stratosphere. In fact, at the surface, this fluctuation which we called the biennial pulse contributes only a few percent of the variance in the monthly-averaged data. On the other hand, there is a much larger amount of surface material available and the series are much longer. If any significance is to be attached to this pulse at all then its persistence through a long history and its geographical distribution might lead us to further interpretations. The existence of a pulse of similar length in lake levels, 

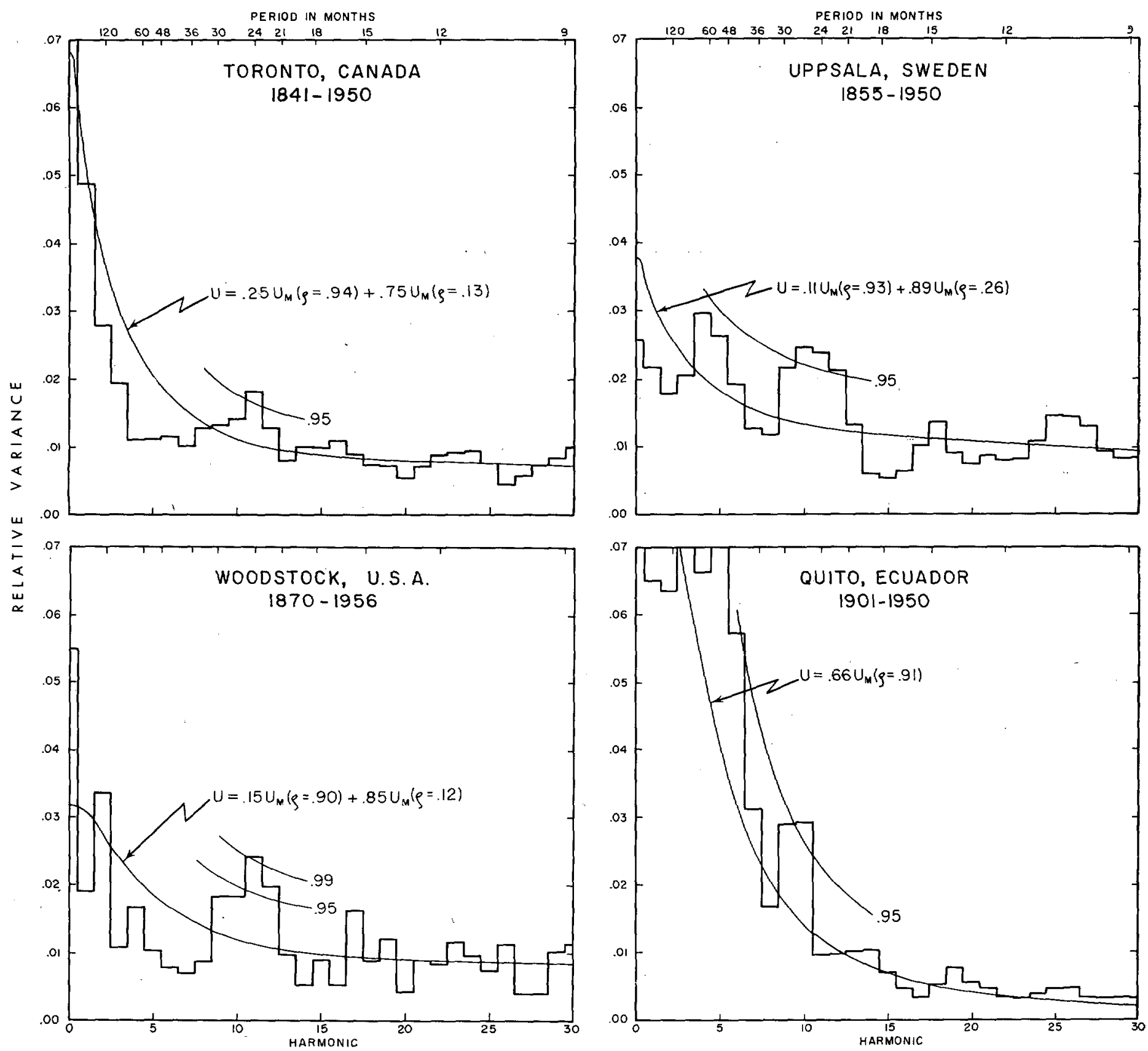

Figure 1.-Power spectra of monthly mean temperature at selected stations, showing first 30 harmonies from analyses with maximum lig of 132 months. Data were "prewhitened" to remove annual march by the formula $T "=T-\bar{T}+\overline{\bar{T}}$, where $\bar{T}$ is the record-mean temperature in the same month as $T$, and $\overline{\bar{T}}$ is the record-mean annual temperature. Fitted "red noise" continua, and their 95 percent confidence limits in the neighborhood of the biennial pulse, are shown by the smooth curves (see text).

varves, and, perhaps, tree rings suggests that we are concerned with a very long-lived [10] element of the atmospheric circulation.

\section{POWER SPECTRA OF TEMPERATURE SERIES}

Through power spectrum analysis, evidence for the presence of this pulse has been found in various other data series. Thus we found it as the most prominent peak of an otherwise "white" spectrum of the combined tempera- tures of 13 Midwestern and Great Plains stations. An analysis of the long combined temperature series (for Vienna, Berlin, deBilt) of Baur [3] also showed this as the most prominent cyclical feature for the interval 1761 to 1953 [10].

In figure 1, added to the Woodstock spectrum already mentioned, are further series of spectra in which this pulse is evident. These cover extended time intervals at Toronto, Ontario, Canada; Uppsala, Sweden; and Quito, 
Ecuador. In each of these spectra, the biennial peak, centered near harmonics 10 and 11 , is found to be significant at the 95 percent level when referred to a null-hypothesis continuum of red noise [8] shown by the smooth curve. ${ }^{1}$

A further argument in favor of the reality of this oscillation is the fact that it is common to locations separated far beyond the limits of the usual high spatial correlation. Thus one might have attributed to spatial correlation the effects in Sweden and central Europe, or those in Canada, the Midwest, and the Middle Atlantic area, but the prevalence of the pulse in data from three continents stamps this as a feature of the general circulation at large.

\section{FILTERED SERIES}

Rather than to analyze further series as power spectra it seemed more interesting to relate phases and amplitudes of the biennial pulse at various localities. For this purpose several long series were subjected to a band-pass filtering technique suggested by Brier [5]. By this technique, it is possible to filter out all frequencies of variation in a time series except those near a preselected frequency of interest, and at the same time to preserve amplitude and phase information concerning the latter with a very high degree of fidelity.

In particular, we used a 55-term weighted movingaverage filter with the weight values shown in table 1 . The response of this filter (applied to monthly data) is unity at a period of 24 months, and falls gradually to zero at periods of $13 \frac{1}{2}$ on the high-frequency side and of about 60 months on the low-frequency side, remaining virtually zero outside these limits. In other words, the filter in table 1 passes with negligible distortion of phase and amplitude all fluctuations with a period near 24 months, and also passes (with more or less reduced amplitude) all fluctuations with periods not exceptionally longer or shorter than 24 months. In this way, irregular variations of phase, exact period, and amplitude of a "biennial pulse" can be followed through the full length of the time series subjected to the filter. ${ }^{2}$

The data chosen for band-pass filter analysis are from stations along two meridans, $70^{\circ}-80^{\circ} \mathrm{W}$. and $10^{\circ}-20^{\circ} \mathrm{E}$. It was hoped in this way to sample the dependence of phase and amplitude of the biennial pulse on both latitude and intercontinental differences of longitude. Although the series of pressure values have been analyzed along with those of temperature at the selected stations, the results reported here pertain almost exchusively to tem-

\footnotetext{
1 In each spectrum in figure 1 (except that for Quito), the continuum is given by the sum of two appropriately weighted Markov red-noise spectra with parameters estimated from the shape of the corresponding autocorrelation function (see [8] footnote 3). The spectrum for Quito is unusual in that only part of its variance could be attributed to Markovian persistence; hence its continuum is shown as a fractional part of a single Markov component

2 If the last 27 values of a time series are averaged, and the series is extended 27 additional months by entering this average 27 times, application of the filter in table 1 to the augmented time series will preserve phase (but not amplitude) information about the biennia pulse right up to the ending date of the series. The beginning of a series may be similarly extended if desired.
}

TABLE 1.-Weights for band-pass filter with maximum response at period of 24 months. Total number of weights is 55 . Values are symmetric about central weight (No. $O$ ). Filtered value of time series belongs to date associated with central weight

\begin{tabular}{|c|c|c|c|}
\hline Weight number & Value & Weight number & Value \\
\hline $\begin{aligned} & 0 \text { (Central weight) } \\
&- 1,1 \\
&- 2,2 \\
&= 3,3 \\
&= 4,4 \\
&- 5,5 \\
&= 6,6 \\
&= 7,7 \\
&= 8,8 \\
&= 9,9 \\
&= 10,10 \\
&-11,11 \\
&-12,12 \\
&-13,13\end{aligned}$ & $\begin{array}{r}.0602 \\
.0577 \\
.0512 \\
.0410 \\
.0279 \\
.0133 \\
-.0017 \\
=.0158 \\
-.0279 \\
-.0372 \\
-.0431 \\
-.0454 \\
-.0442 \\
-.0400\end{array}$ & $\begin{array}{l}-14,14 \\
-15,15 \\
-16,16 \\
-17,17 \\
-18,18 \\
-19,19 \\
-20,20 \\
-21,21 \\
-22,22 \\
-23,23 \\
-24,24 \\
-25,25 \\
-26,26 \\
-27,27\end{array}$ & $\begin{array}{r}-.0334 \\
-.0253 \\
-.0165 \\
-.0079 \\
.0000 \\
.0065 \\
.0115 \\
.0147 \\
.0163 \\
.0165 \\
.0156 \\
.0140 \\
.0121 \\
.0100\end{array}$ \\
\hline
\end{tabular}

perature. This is because the biennial peak in the spectra of pressure at most of the stations was found not to be as marked as that of temperature. Inasmuch as the filtering procedure produces of necessity a rather regularly periodic output even for purely random series, it was felt that the results for pressure might be dominated by irrelevant random noise effects. ${ }^{3}$

Interpretation of the results for temperature must properly allow for random noise effects also. The spectra in figure 1 indicate that roughly half of the variance of temperature derived from periods near $2 \mathrm{yr}$. is associated with background "red noise". Some distortion of the biennial pulse in the filtered series is therefore to be anticipated, especially at times when the pulse itself is comparatively weak.

The filtered temperature series are shown in figure 2 for a selected 40-yr. period of record 1908-1947. They are arranged in geographical order of latitude along each of the two meridians, and all are scaled in units of ${ }^{\circ} \mathrm{C}$.

As a measure of the practical significance of the biennial pulse in surface temperature, the median and maximum double amplitudes of the pulse in the period 1908-1947 are compared in table 2 with the mean 10-yr. range of annual mean temperature in the same period. ${ }^{4}$ Table 2 shows that the median amplitude to each location approximates to half of the $10-y r$. range, and that the maximum amplitude tends to exceed the range somewhat. However, since about half of the variance in the filtered series derives from noise the importance of the real pulse is about one-third less than that suggested in table 2 .

\section{PHASE RELATIONS}

Inspection of the data in figure 2 leads one to the following conclusions.

(a) Western Meridian $\left(70^{\circ}-80^{\circ} W\right.$.). The pulses at Quito (on the equator) and Colón $\left(9^{\circ} \mathrm{N}\right.$.) are consistently

\footnotetext{
a It should be remarked that a study of meridional pressure gradients may be more pertinent to a physical understanding of the biennial pulse. Such a study is being planned by the writers.

4 The mean 10-yr. range was chosen in lieu of the total 40-yr. range to deemphasize the effect of secular trends in the series.
} 


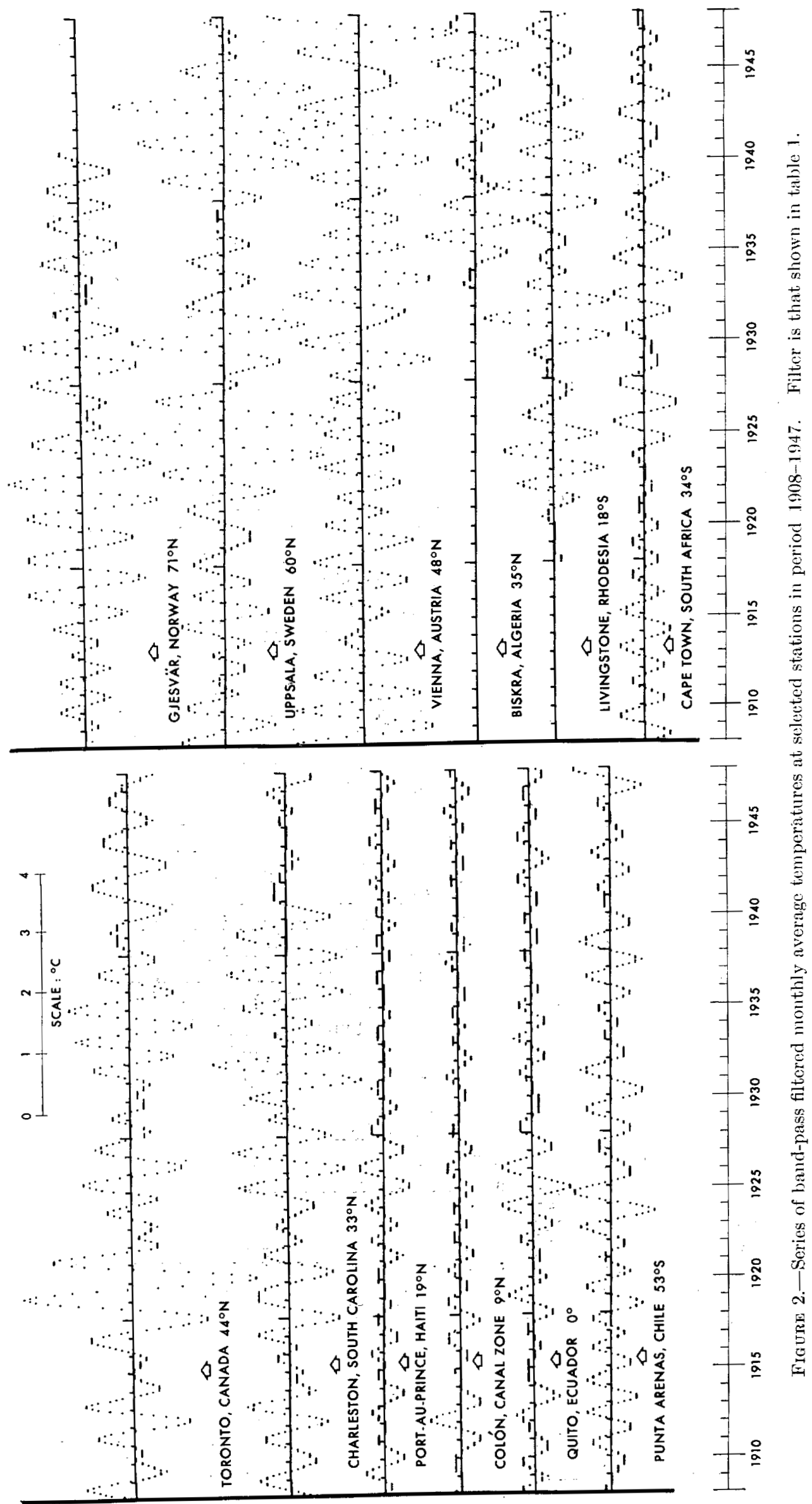


TABLE 2.-Comparison of median and maximum amplitudes of biennial pulse of temperalure with range of annual mean temperature, in period 1908-1947. Data shown in ${ }^{\circ} \mathrm{C}$. for all stations in figure 2 having complete record in period

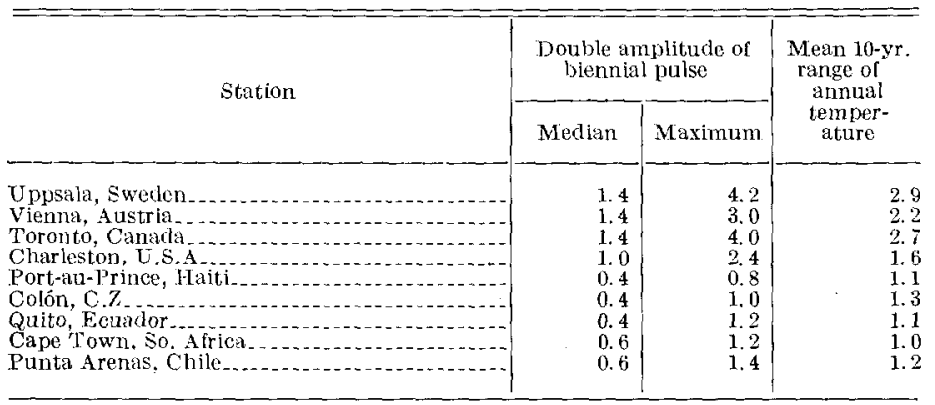

in phase. The pulse at Port-au-Prince $\left(19^{\circ}\right.$ N.) is also in phase with these during the first half of the 40-yr. record, but varies independently thereafter. The pulses at Charleston $\left(33^{\circ} \mathrm{N}\right.$.) and at Toronto $\left(44^{\circ} \mathrm{N}\right.$.) are mutually in phase, and both are consistently about $180^{\circ}$ out of phase with those at Quito and Colón. The pulse at Punta Arenas $\left(53^{\circ} \mathrm{S}\right.$.) has some tendency also to be out of phase with those at Quito and Colón, and in phase with those at Charlestown and Toronto; however this last relationship is quite vague.

$\begin{array}{lll}\text { (b) Eastern Meridian }\left(10^{\circ}-20^{\circ}\right. & \text { E. }) \text {. The pulse at }\end{array}$ Livingstone $\left(18^{\circ} \mathrm{S}\right.$.), the only station on this meridian located rather near the equator, has some tendency to remain out of phase with those at Vienna $\left(48^{\circ} \mathrm{N}\right.$.), Uppsala $\left(60^{\circ}\right.$ N.), and Gjesvar $\left(71^{\circ}\right.$ N.). The latter three are all consistently in phase with one another. Based on the short available record at Biskra $\left(35^{\circ} \mathrm{N}.\right)$, the pulse in North Africa is not clearly related in phase to the pulses elsewhere except perhaps at Cape Town $\left(34^{\circ} \mathrm{S}\right.$.). The pulse at Cape Town tends only loosely to be out of phase with the pulses at Livingstone and Biskra.

(c) Comparison between meridians. On examination of the phase relationships between stations along different meridians, some conclusions are the following. Among the higher northern-latitude stations, the phase relationship between meridians is not systematic.. In the high southern latitudes, however, the pulses at Cape Town and Punta Arenas are found to be quite consistently and almost exactly $180^{\circ}$ out of phase during the full $40-\mathrm{yr}$. period.

In the Tropics, a conclusive evaluation of the phase relationship between meridians is complicated by the rather dissimilar station latitudes. The most logical comparison would appear to be one between Quito and Livingstone. The pulses at these locations are consistently in phase with one another between tbe beginning date of the Livingstone record (1918) and 1934, but bear a shifting relationship thereafter (1934 to 1948). This result is particularly interesting in view of the fact that, since 1954 at least, the phase of the biennial stratospheric wind oscillation has been very similar at widely separated
TABLE 3.-Number of maxima in biennial pulse occurring each month of the year, 1908-194\%

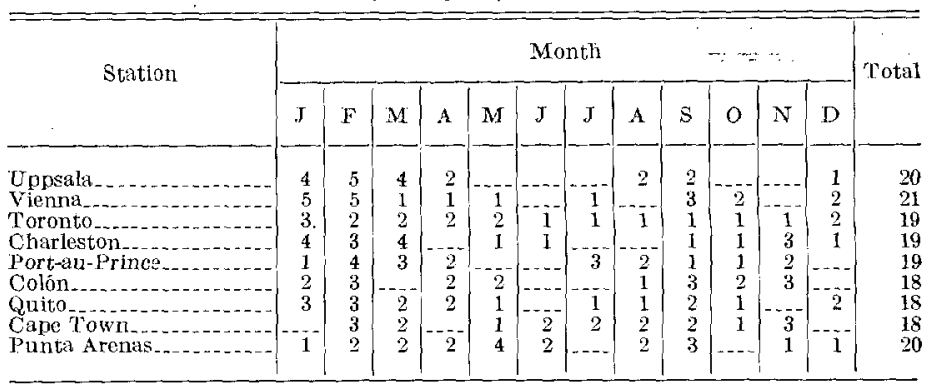

longitudes in the Tropics [14]. Our result would imply that this may not be true at all times.

To summarize the conclusions concerning phase, a rather abrupt reversal of phase appears to exist along both meridians between the Tropics and extratropical latitudes, particularly in the Northern Hemisphere. The latitude of this phase reversal is evidently near the axis of the subtropical high-pressure belts, delimiting the Hadley cell of the general circulation. This is in line with phase changes found in stratospheric temperature, at about the same latitudes, by Angell and Korshover [2]. In the tropical zone along both meridians, the pulse is in mutual phase for part but not all of the 40-yr. period of the analysis. In the higher southern latitudes, the pulse is uniformly out of phase between the two meridians, but no corresponding relation is obvious in the higher northern latitudes.

Amplitude variations of the pulse, appear not to have any systematic relationship at the different stations. It may tentatively be concluded that the spatial correlation of pulse amplitude decays with distance at a rate comparable to that of climatic temperature in general. At most of the stations, there is some tendency for the amplitude of the pulse to oscillate with periods between about 7 and $9 \mathrm{yr}$.

An especially noteworthy aspect of the biennial pulse is its tendency to become locked in phase with the season of the year. This is evident from table 3 , which shows for each full-record station in figure 2 the number of times the pulse reached a maximum in each month of the year between 1908 and 1947. At all the Northern Hemispheric stations, there is some preference for the maxima to occur in winter (especially January, February, and March). Quito, on the equator, appears to be in step with the Northern Hemisphere in this respect. On the other hand, the phase of the pulse at the Southern Hemispheric stations shows a much weaker seasonal locking, tending merely to avoid the high-summer months (December and January).

To clarify further the matter of phase locking with season, the entire temperature series at two of the longest record stations: in this study (Uppsala and Charleston) were filtered in the same way as before. The results, 
TABLE 4.-Number of maxima and minima in biennial pulse occurring each month of the year, and mean double amplitude $\left({ }^{\circ} \mathrm{C}.\right)$, based on full period of record at two stations

\begin{tabular}{l|l|l|l|l|l|l|l|l|l|l|l|l}
\hline & \multicolumn{10}{|c}{ Month } \\
& J & F & M & A & M & J & J & A & S & o & N & D \\
\hline
\end{tabular}

summarized in table 4 , indicate that the pulse phase at both stations leans strongly toward winter. ${ }^{5}$ This is shown not only by a higher frequency of maxima and minima reached during winter, but also by a larger mean amplitude of the pulse at times when its extremes coincide with winter. If the fundamental period of the biennial pulse is not precisely $2 \mathrm{yr}$., then such behavior not only implies some sort of modulation of pulse amplitude by the annual march of relevant climatic variables, but also a tendency for the shape of the pulse to be distorted when the maxima and minima occur other than in winter.

The 7- to 9-yr. oscillation of pulse amplitude at many stations, mentioned earlier may be a different manifestation of the same modulation phenomenon, inasmuch as a pulse whose fundamental period is $27-28$ months would pass through 3 cycles in just about 7 yr., 31/2 cycles in 8 yr., and 4 cycles in $9 \mathrm{yr}^{6}$

\section{LONG SERIES}

The filtered temperature series for the full length of available records at Uppsala and Toronto are shown respectively in figures 3 and 4 . The similarly filtered series of sea level pressures at Toronto is alse shown in figure 4. These series raise some interesting questions. First, some of the earliest known references to the biennial pulse in temperature, made around the turn of the century by Clayton [6], Woeikof $[20,21]$, and Wallén [19], followed an epoch in which the pulse sometimes reached exceptionally large amplitudes. The pulse may therefore have seemed a rather natural subject for investigation at that time. Second, the biennial pulse in Toronto pressure is typical of the situation at the other stations

\footnotetext{
3 Nonetheless, some investigators have noted the oscillation in indices of summer heat, such as Sutton [16] for London and Schindler [15] for Frankfurt am Main.

${ }^{8}$ It may be added that a $27-28$-month eycle would again be in phase with the (winter) season aftes from 6 to $8 \mathrm{cscles}$, or at intervals of from about 14 to $17 \mathrm{yr}$. This is comparable to the intervals between the spells of ontstandingly Iarge-amplitude pulses at Toronto and Uppsala, for example.
}

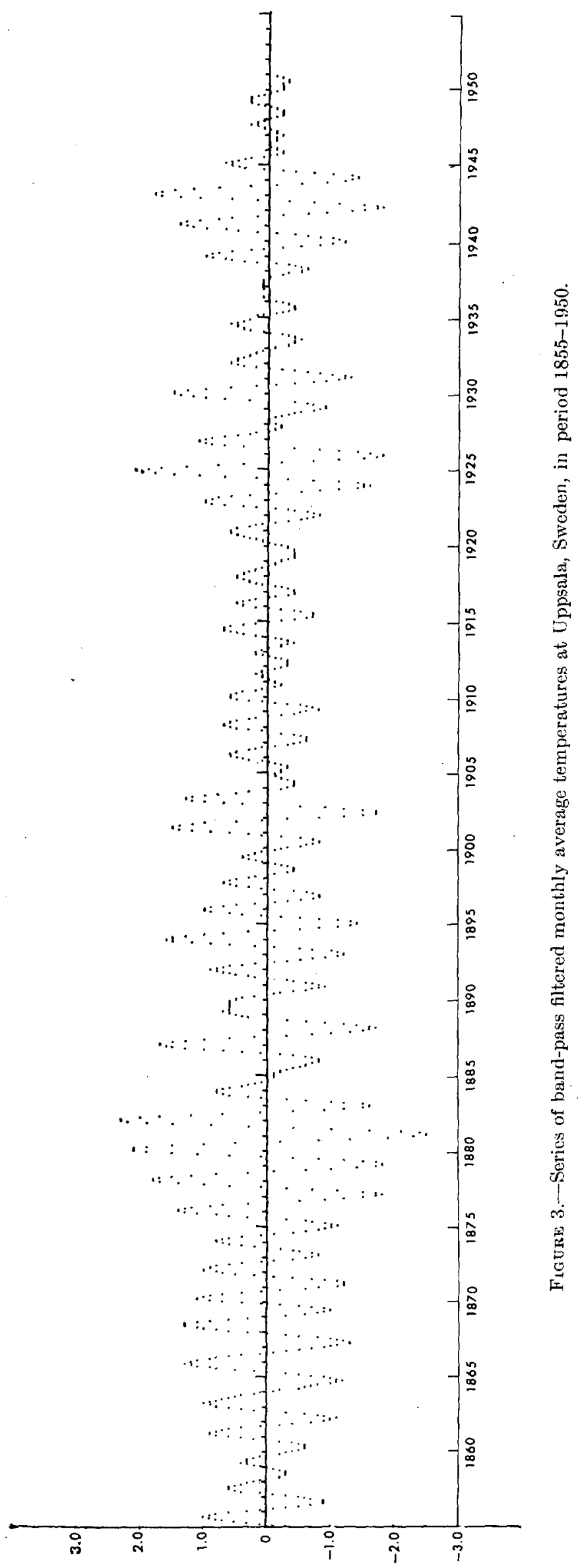




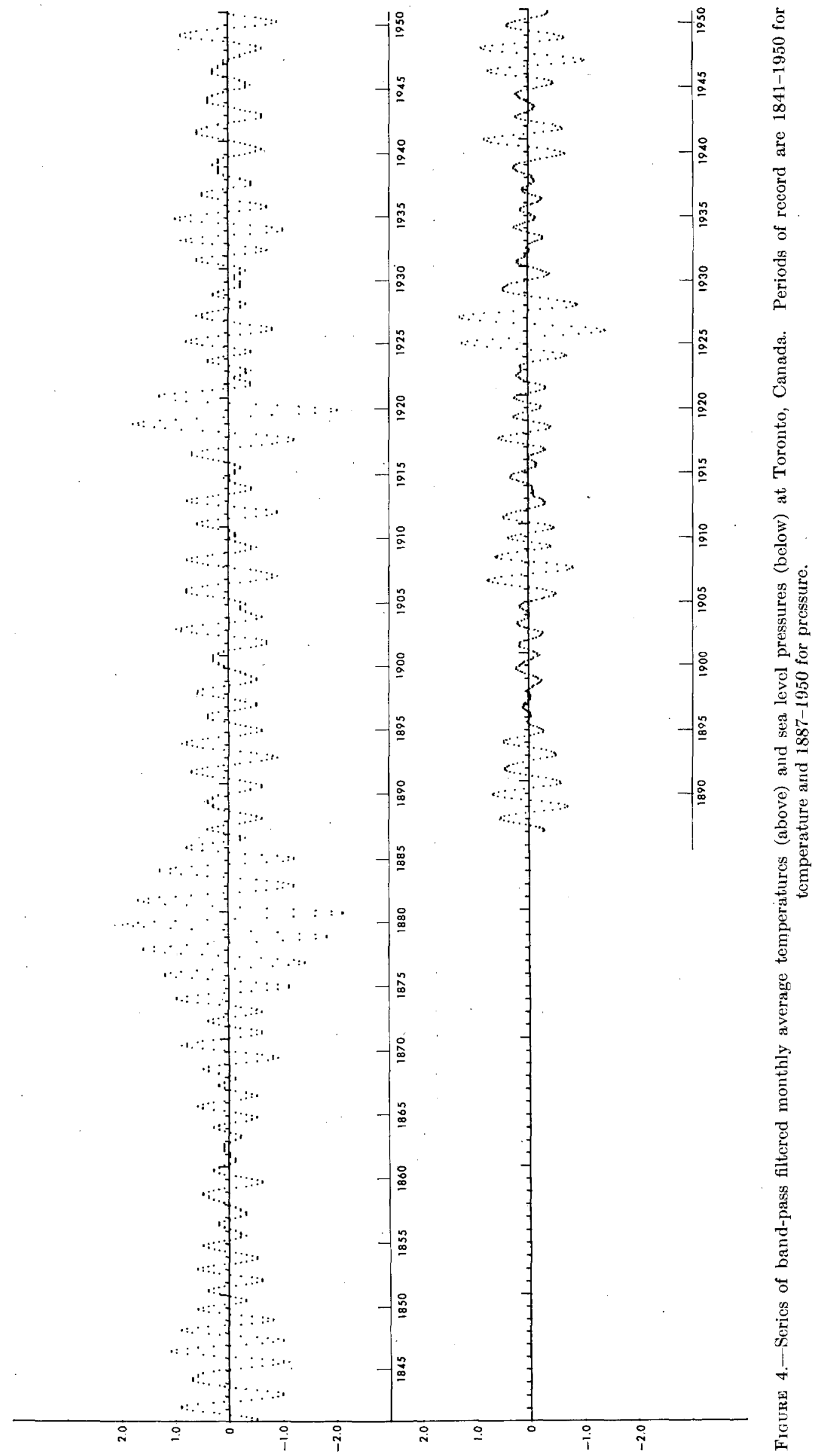


we studied in showing no systematic phase or amplitude relationship with the corresponding temperature pulse. On the other hand, the Toronto pressure pulse is unique in showing a rather striking variation of amplitude at intervals of about 19 or $20 \mathrm{yr}$. (since 1887). Although possibly only spurious, this phenomenon is the more intriguing because it coincides with a similarly regular recurrence of wet and dry periods in the Central Plains of the United States [12]. The periods of large pulse amplitude in Toronto pressure coincided with wet periods in the Plains, and those of small pulse amplitude with dry periods.

\section{CONCLUSIONS}

Our data leave no doubt that the pulse, slightly in excess of 2 years in period, is a worldwide phenomenon. They also show that this has been a fairly persistent feature during the past century. Although there is no definite proof of this as yet, it appears reasonable to suppose that the intertropical region may be the seat of the perturbation. This we hope to explore further in studies of time series of pressure gradients.

\section{ACKNOWLEDGMENTS}

The writers are grateful to Messrs. Glenn W. Brier and Thomas H. Carpenter, U.S. Weather Bureau, for their assistance in designing the band-pass filter used in this paper. They acknowledge also the invaluable help of Messrs. Grady McKay and M. Larry Snelson, of the National Weather Records Center, in preparing the computer programs for the spectrum and filter analysis.

\section{REFERENCES}

1. J. K. Angell and J. Korshover, "The Biennial Wind and Temperature Oscillations of the Equatorial Stratosphere and Their Possible Extension to Higher Latitudes," Monthly Weather Review, vol. 90, No. 4, Apr. 1962, pp. 127-132.

2. J. K. Angell and J. Korshover, "Harmonic Analysis of the Biennial Zonal-Wind and Temperature Regimes," Monthly Weather Review, vol. 91, Nos. 10-12, Oct.-Dec. 1963, pp. $537-548$

3. F. Baur, "Langjahrige Beobachtungsreihen," Linke's Meteorologisches Taschenbuch, Neue Ausgabe, vol. II, 1953, pp. 610-614.

4. H. P. Berlage, "The Southern Oscillation, a 2-3 Year Fundamental Oscillation of World-Wide Significance," I. L. G. G. 10th General Assembly, Rome 1954, Scientific Proceedings International Association of Meteorology, London, 1956, pp. 336-345.

5. G. W. Brier, "Some Statistical Aspects of Long-Term Fluctuations in Solar and Atmospheric Phenomena," Annals of the New York Academy of Sciences, vol. 95, Art I, Oct. 1961, pp. 173-187.

6. H. H. Clayton, "A Lately Discovered Meteorological Cycle," American Meteorological Journal, vol. 1, 1885, pp. 130, 528.

7. J. P. Funk and G. L. Garnham, "Australian Ozone Observations and a Suggested 24 Month Cycle," Tellus, vol. 14, No. 4, Nov. 1962, pp. 378-382.

8. D. L. Gilman, F. J. Fuglister and J. M. Mitchell, Jr., "On the Power Spectrum of 'Red Noise'," Journal of the Atmospheric Sciences, vol. 20, No. 2, Mar. 1963, pp. 182-184.

9. H. H. Lamb, J. R. Probert-Jones, and J. W. Sheard, "A New Advance of the Jan Mayen Glaciers and a Rernarkable Increase of Precipitation," Journal of Glaciology, vol. 4, No. 33 , Oct. 1962, pp. 355-365.

10. H. E. Landsberg, "Biennial Pulses in the Atmosphere," Beiträge zur Physik der Atmosphäre, vol. 35, No. 3/4, 1962, pp. 184-194.

11. H. E. Landsberg, J. M. Mitchell, Jr., and H. L. Crutcher, "Power Spectrum Analysis of Climatological Data for Woodstock College, Maryland," Monthly Weather Review, vol. 87, No. 8, Aug. 1959, pp. 283-298.

12. W. C. Palmer, "Meteorological Drought: Its Measurement and Classification," U.S. Weather Bureau Manuscript, 1961 (to be published in Weather Bureau Research Paper Series).

13. R. J. Reed, W. J. Campbell, L. A. Rasmussen, and D. G. Rogers, "Evidence of a Downward-Propagating, Annual Wind Reversal in the Equatorial Stratosphere," Journal of Geophysical Research, vol. 66, No. 3 Mar. 1981, pp. 813-818.

14. R. J. Reed and D. G. Rogers, "The Circulation of the Tropical Stratosphere in the Years 1954-1960," Journal of the Atmospheric Sciences, vol. 19, No. 2, Mar. 1962, pp. 127-135.

15. G. Schindler, "Eigenartiges Thermisches Verhalten der Sommer im Frankfurter Raum," Meteorologische Rundschau, vol. 12, 1959, pp. 189-190.

16. O. G. Sutton, "Summers in London," Weather, vol. 17, No. 12, Dec. 1962 , p. 408

17. R. G. Veryard and R. A. Ebdon, "Fluctuations in Equatorial Stratospheric Winds," Nature, vol. 189, 1961, pp. 791-793.

18. R. G. Veryard and R. A. Ebdon, "Fluctuations in Tropical Stratospheric Winds," Meteorological Magazine, vol. 90, No. 1066, May 1961, pp. 125-143.

19. A. Wallén, "Temperatur-, Niederschlag- und Wasserstandsschwankungen in. Nordeuropa," Meteorologische Zeitschrift, vol. 31,1914 , pp. 209-220.

20. A. I. Woeikof, "Perioden in der Temperatur von Stockholm," Meteorologische Zeitschrift, vol. 23, 1906, pp. 433-436.

21. A. I. Woeikof, 'Die Schneedecke in 'paaren' und 'unpaaren' Wintern," Meteorologische Zeitschrift, vol. 12, 1895, pp. 77-78. 